Article

\title{
Optimum Compressive Strength of Hardened Sandcrete Building Blocks with Steel Chips
}

\author{
Alohan Omoregie \\ School of Built Environment and Engineering, University of Bolton (UK), UAE Campus, \\ Al Hudaiba-Bareraat, P.O. Box 16038, Ras al Khaimah, UAE; E-Mails: a.omoregie@bolton.ac.uk \\ and omoregiealohan@hotmail.co.uk
}

Received: 24 September 2012; in revised form: 5 December 2012 / Accepted: 29 January 2013 / Published: 18 February 2013

\begin{abstract}
The recycling of steel chips into an environmentally friendly, responsive, and profitable commodity in the manufacturing and construction industries is a huge and difficult challenge. Several strategies designed for the management and processing of this waste in developed countries have been largely unsuccessful in developing countries mainly due to its capital-intensive nature. To this end, this investigation attempts to provide an alternative solution to the recycling of this material by maximizing its utility value in the building construction industry. This is to establish their influence on the compressive strength of sandcrete hollow blocks and solid cubes with the aim of specifying the range percent of steel chips for the sandcrete optimum compressive strength value. This is particularly important for developing countries in sub-Saharan Africa, and even Latin America where most sandcrete blocks exhibit compressive strengths far below standard requirements. Percentages of steel chips relative to the weight of cement were varied and blended with the sand in an attempt to improve the sand grading parameters. The steel chips variations were one, two, three, four, five, ten and fifteen percent respectively. It was confirmed that the grading parameters were improved and there were significant increases in the compressive strength of the blocks and cube samples. The greatest improvement was noticed at four percent steel chips and sand combination. Using the plotted profile, the margin of steel chips additions for the optimum compressive strength was also established. It is recommended that steel chip sandcrete blocks are suitable for both internal load bearing, and non-load bearing walls, in areas where they are not subjected to moisture ingress. However, for external walls, and in areas where they are liable to moisture attack after laying, the surfaces should be well rendered. Below ground level, the surfaces should
\end{abstract}


be coated with a water proofing agent like bitumen and cement containing waterproofing agents be used in the manufacture, laying, and rendering of steel chip sandcrete blocks.

Keywords: steel chips; optimum compressive strength; sandcrete-blocks; sandcrete-cubes

\section{Introduction}

The purpose of this paper is to ascertain the range of added steel chips for optimum compressive strength value of hardened sandcrete building hollow blocks and cubes with steel chips; in the process, establish how compressive strength can be improved using steel chips. For clarity, sandcrete is a composite material consisting of fine aggregate (sand), cement, and water at an appropriate ratio. The material can be used in the manufacture of blocks and also as a binder for precast units in early stages before they set and harden. Sandcrete blocks are used predominantly in partition or load bearing walls. They transmit structural loads from the overlaying structural element down to foundations for stability. For this reason, sandcrete blocks are globally considered appropriate and very adaptable in the building materials industry.

However, for some time now, the majority of sandcrete blocks used in developing countries, especially in sub-Saharan Africa, have often fallen short of local and global specification standards. In the Nigerian building industry, for example, the majority of the sandcrete blocks in use do not meet specification standards recommended by the Nigerian Federal Ministry of Works [1-3]. Earlier investigations in Nigeria have also revealed the very poor performance of these sandcrete blocks as they exhibit compressive strength far below the standard requirements [4]. Some of these blocks frequently fail due to their own weight, even when being transported. Therefore, it is not surprising to see frequent cases of building failure, in particular failures of walls made from these blocks. Several studies have also shown that poor quality control and the use of sub-standard building materials are chiefly responsible for the high failure rates of building structures in Nigeria [1-3,5-7].

As cited in [1,8] structural failure is a direct function of constituent material failures and the interactions of materials within structural units. To this end, several factors, which include the influence of fine aggregate combinations on particle size distribution, grading parameters, and compressive strength of sandcrete blocks, have been investigated [2]. The impact of vibration time on the compressive strength of hardened sandcrete building blocks has also been assessed [3]. The sole objective of this paper is to show how steel chips (a waste industrial product from mechanical workshops and factories) can be used to improve the compressive strength of sandcrete hollow blocks and cubes and obtain the range of steel chips percent for optimum compressive strength for these blocks and cubes. At this stage it is important to present the program of study for this investigation.

\section{Program of Investigation}

The program of investigation is subdivided into two phases. The first phase involves the addition of some proportions of steel chips, by weight (percentage of steel chips in relation to the weight of cement), to the sandcrete mix. These proportions are 5\%,10\% and $15 \%$ respectively. However, it is 
important to mention here that these proportions were arbitrarily chosen at the beginning, and not informed by previous work or research. Then, blocks and cube samples are produced using each of these proportions. It is important to indicate that none of the proportions of steel chips used affects the proportion of the sandcrete constituents (sand, cement, water). So the added steel chips' proportions were only additions to the sandcrete mix.

The second phase of this investigation is based on the experimental compressive strength results obtained during the first phase (where the influence of 5\%,10\% and 15\% steel chips were investigated). In other words, the first phase investigation helped determine whether to increase or decrease the proportion of steel chips used in the second phase. For instance, if the first phase results show an increase in compressive strength due to the increase in the amount of added steel chips; then in the second phase investigation an additional set of increased steel chips proportions has to be investigated to ascertain the range of the optimum compressive strength. In this instance, the highest compressive strength obtained out of the three percentages of added steel chips above was $5 \%$ followed by $10 \%$ and then $15 \%$. This suggests that the position of the optimum compressive strength value is likely at the $5 \%$ added steel chips; it could also be slightly less, or far less, than $5 \%$. So there is need to further investigate the influence of lower proportions of added steel chips i.e., $1 \%, 2 \%, 3 \%$, and $4 \%$ respectively to ascertain the range of steel chips percent additions for optimum compressive strength value for both hollow sandcrete blocks and cubes. A total of 162 samples were used (produced and tested) in this investigation: 36 blocks and 36 cubes for the first phase and another 36 blocks and 36 cubes for the second phase investigation; totaling 144 samples. The remaining 18 samples (comprising nine blocks and nine cubes) were used for the wet compressive strength test. "Wet compressive strength is the strength test conducted after 28 day cured blocks are submerged in water for another 14 days before undergoing the compressive strength test" [2]. See Tables 1-3 below for the number of the samples (blocks and cubes) at various testing periods (7-day, 14-day, 28-day).

Table 1. Number of blocks at the various testing periods.

\begin{tabular}{ccccc}
\hline Aggregate & 7-day & 14-day & 28-day & Number of samples \\
\hline Sand + Steel Chips (0\%) & 3 & 3 & 3 & 9 \\
Sand + Steel Chips (1\%) & 3 & 3 & 3 & 9 \\
Sand + Steel Chips (2\%) & 3 & 3 & 3 & 9 \\
Sand + Steel Chips (3\%) & 3 & 3 & 3 & 9 \\
Sand + Steel Chips (4\%) & 3 & 3 & 3 & 9 \\
Sand + Steel Chips (5\%) & 3 & 3 & 3 & 9 \\
Sand + Steel Chips (10\%) & 3 & 3 & 3 & 9 \\
Sand + Steel Chips (15\%) & 3 & 3 & 3 & 9 \\
Total number of blocks tested & 24 & 24 & 24 & 72 \\
\hline
\end{tabular}


Table 2. Number of cubes at the various testing periods.

\begin{tabular}{ccccc}
\hline Aggregate & 7-day & 14-day & 28-day & Number of samples \\
\hline Sand + Steel Chips (0\%) & 3 & 3 & 3 & 9 \\
Sand + Steel Chips (1\%) & 3 & 3 & 3 & 9 \\
Sand + Steel Chips (2\%) & 3 & 3 & 3 & 9 \\
Sand + Steel Chips (3\%) & 3 & 3 & 3 & 9 \\
Sand + Steel Chips (4\%) & 3 & 3 & 3 & 9 \\
Sand + Steel Chips (5\%) & 3 & 3 & 3 & 9 \\
Sand + Steel Chips (10\%) & 3 & 3 & 3 & 9 \\
Sand + Steel Chips (15\%) & 3 & 3 & 3 & 9 \\
Total number of cubes tested & 24 & 24 & 24 & 72 \\
\hline
\end{tabular}

Table 3. Numbers of blocks and cubes for wet compressive strength test.

\begin{tabular}{ccc}
\hline Aggregate combinations & Type of sample & 14-day test \\
\hline Sand + Steel Chips (5\%) & Block & 3 \\
Sand + Steel Chips (10\%) & Block & 3 \\
Sand + Steel Chips (15\%) & Block & 3 \\
Sand + Steel Chips (5\%) & Cube & 3 \\
Sand + Steel Chips (10\%) & Cube & 3 \\
Sand + Steel Chips (15\%) & Cube & 3 \\
Total number of blocks tested & - & 18 \\
\hline
\end{tabular}

\section{Methodology}

\subsection{Sampling of Fine Aggregate}

The Riffler method was adopted as the sampling technique for the sand used in this investigation $[9,10]$. The riffling process ensures that the real sand sample for testing is a representative character of the bulk by splitting the sample into multiple halves using a box with a number of alternate and parallel vertical divisions. This aggregately splits the sand into two halves; collected in "two boxes at the bottom of the chutes on each side". Discarding one half (one of the boxes), and riffling the other repeatedly to reduce the sample to desired weight.

\subsection{Sieve Analysis}

The particle size distribution was mechanically carried out as described in the British Standards $[11,12]$. So the sieve analysis was conducted on the following steel chips, sands, and various sand and steel chips combinations in order to understand their grading. Some of these are presented as curves on the conventional semi-logarithmic plot (see Figures 1-5 below). Finally, the grading parameters were also numerically expressed [3,13-15], i.e., the uniformity coefficients $\left(\mathrm{C}_{\mathrm{u}}\right)$, curvature coefficients $\left(\mathrm{C}_{\mathrm{c}}\right)$ and the fineness modulus $\left(\mathrm{F}_{\mathrm{m}}\right)$. See Table 5 below. "The uniformity coefficient $\left(\mathrm{C}_{\mathrm{u}}\right)$ defines the steepness of the curve on a semi-logarithmic plot and its value ranges from $\leq 2$ for poorly graded sand to $\geq 6$ for well graded sand. Thus, the larger the $\mathrm{C}_{\mathrm{u}}$, the wider the particle size distribution, and the smaller the $C_{u}$, the narrower the particle size distribution. If $\left(C_{u}\right)=1$ it means all particles 
(grains) are of the same size (uniform). The Curvature coefficients $\left(\mathrm{C}_{\mathrm{c}}\right)$ defines the mid-portion of the curve, which measures the possibility for dense packing (width of the density function) and it also gives an indication of the shape of the grading curve (second moment or standard deviation of the curve). Its value ranges from one to three for well-graded soil [3].

Figure 1. Grading curve for the sand used on a semi-logarithmic plot.

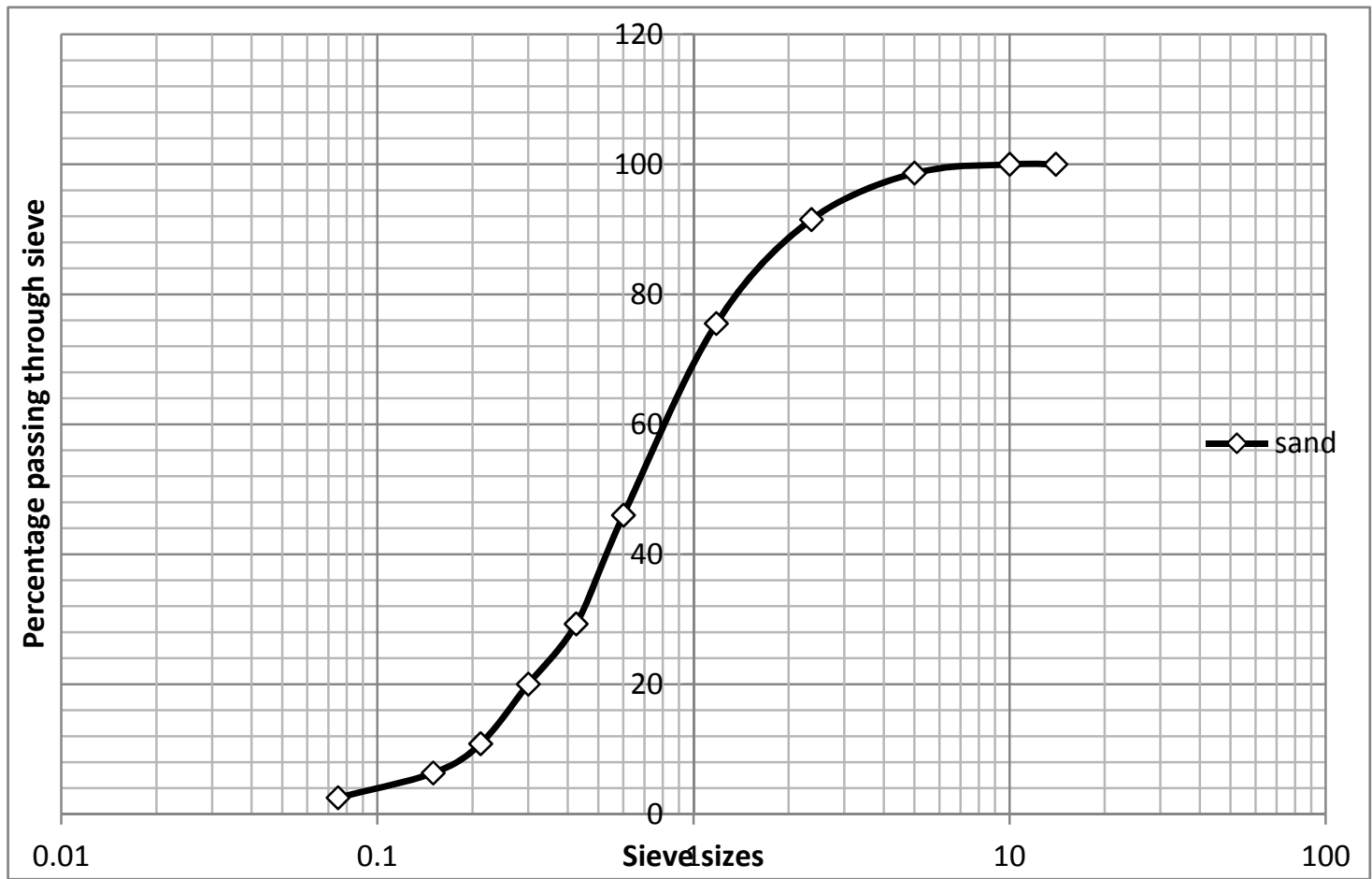

Figure 2. Grading curves for the steel chips on a semi-logarithmic plot.

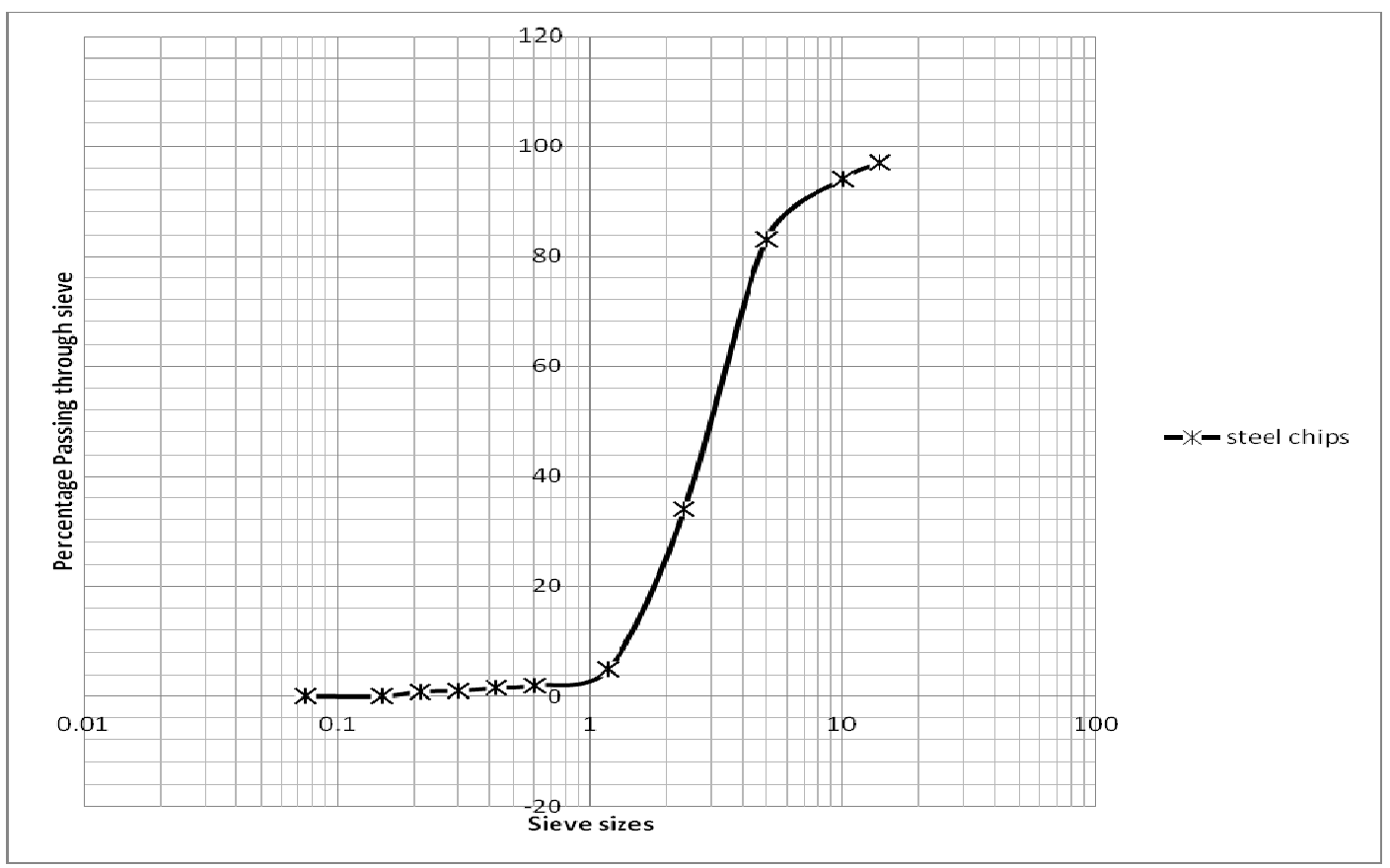


Figure 3. Grading curves for sand and steel chips (5\%) combination.

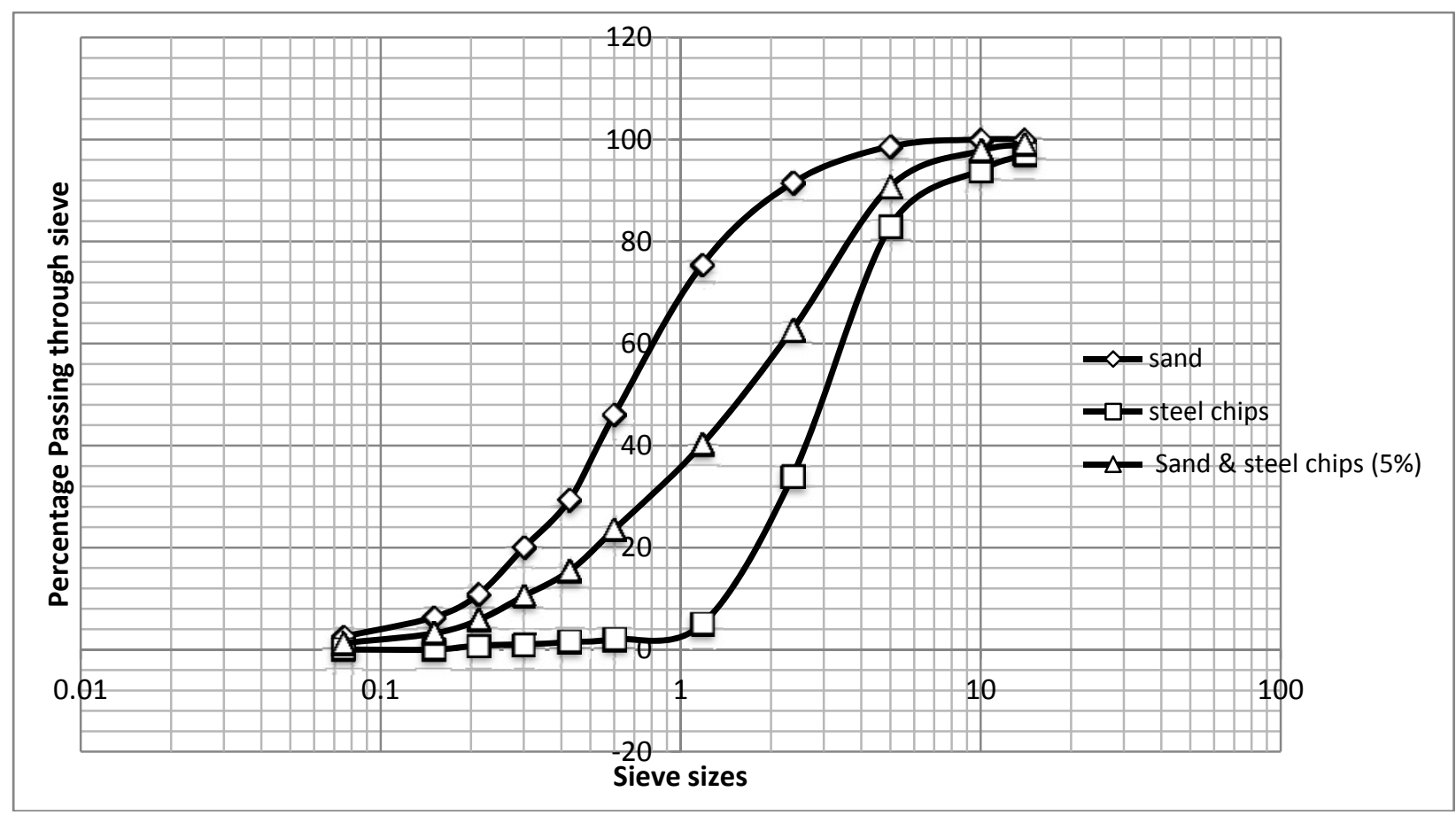

Figure 4. Grading curves for sand and steel chips (10\%) combination.

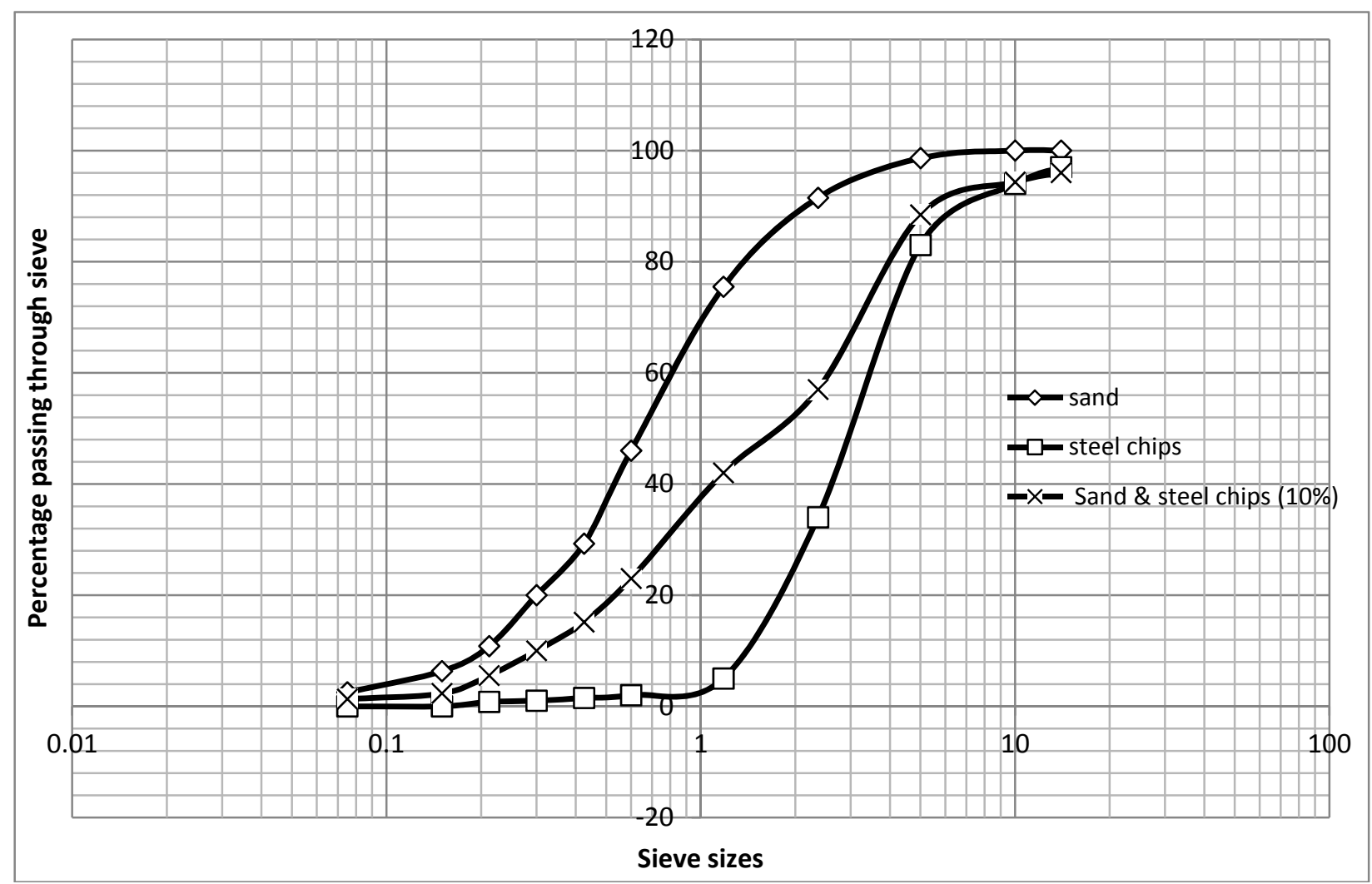


Figure 5. Grading curves for sand and steel chips (15\%) combination.

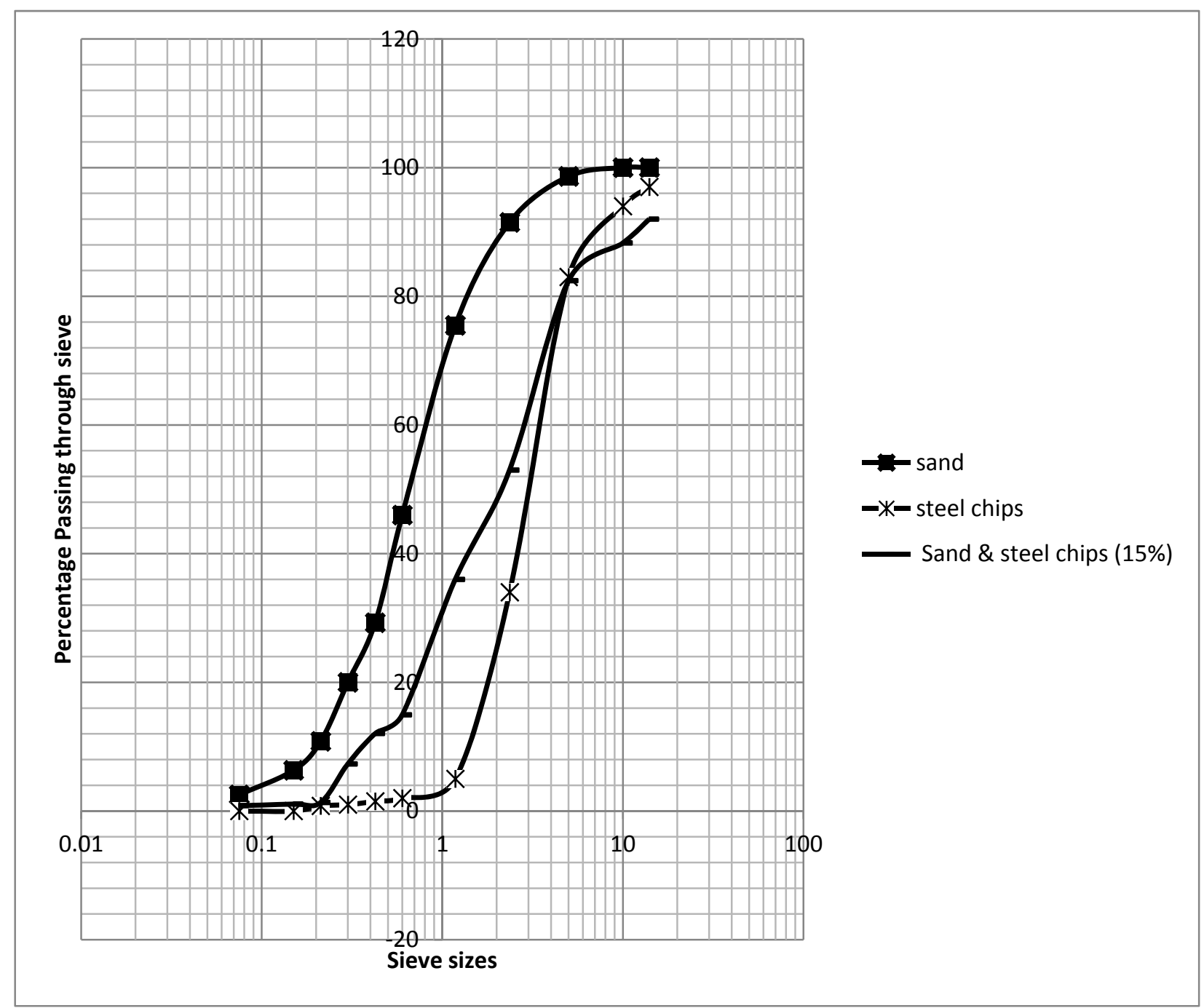

\subsection{Sandcrete Blocks and Cube Production}

The sandcrete blocks and cubes were produced under highly controlled conditions. The recommended standard mix ratio adopted was 1:6 (i.e., one part cement to six parts sand). The optimum moisture content from the compaction test conducted and the actual moisture content of the sand were derived in accordance with the procedures in [11]. Thus, the actual proportion of water added to the mix was the difference between the optimum moisture content and the actual moisture content of the sand. This was carefully done in order to not exceed the optimum moisture content of the sand. All batching was carried out by mass. For example, $100 \mathrm{~kg}$ of sand with optimum moisture content of $11.7 \%$ at ratio 1:6 (sand-cement ratio) would require the following:

$100 \div 6=16.3 \mathrm{Kg}$ cement

$\therefore$ Bulk weight $=100+16.3=116.3 \mathrm{Kg}$

Optimum moisture content at $11.7 \%$ would require:

$(11.7 \times 116.3) \div 100=13 \mathrm{Kg}$ water

$\therefore$ Water-cement ratio $=13 \div 16.3=0.8$ 
The block and cube samples achieved compaction by combining vibration with compression (using high frequency vibrators; molds and a weighted press (ram), anchored to the hydraulic cylinder of the block molding machine). These specimens were all cured in the laboratory by water spray once a day. This curing was done with care in order to ensure that the mortar achieves the minimum strength specified in [16].

\subsection{Compressive Strength Test}

In context, compressive strength is the ratio of the maximum force (or failure load) a sample can sustain to its cross-sectional area (or loaded area). The loaded area of the $150 \mathrm{~mm}$ hollow block sample was $43,500 \mathrm{~mm}^{2}$, and that of the $100 \mathrm{~mm}$ cube sample was $10,000 \mathrm{~mm}^{2}$. So, compressive strength of cubes will definitely be higher compared to that of hollow blocks because of its smaller cross sectional area (loaded area). The dry and wet compressive strength tests were carried out using the destructive test method. The dry compressive strength test is the compressive strength test carried out on the sample after a 7-day, 14-day and 28-day curing period; while the wet compressive strength test is the test conducted after the 28-day cured samples were submerged in water for another 14 days before the test. The compressive strength tests were carried out in accordance with [12] (see Tables 4 and 5 below).

Table 4. Compressive strength loss due to wet compressive strength test.

\begin{tabular}{|c|c|c|c|c|}
\hline Aggregate combinations & Sample type & $\begin{array}{l}\text { Dry compressive } \\
\text { strength }\left(\mathrm{N} / \mathrm{mm}^{2}\right)\end{array}$ & $\begin{array}{l}\text { Wet compressive } \\
\text { strength }\left(\mathrm{N} / \mathrm{mm}^{2}\right)\end{array}$ & $\%$ Strength loss \\
\hline Sand + Steel Chips (5\%) & Block & 3.64 & 1.86 & 49 \\
\hline Sand + Steel Chips $(10 \%)$ & Block & 3.5 & 1.65 & 53 \\
\hline Sand + Steel Chips $(15 \%)$ & Block & 2.34 & 1.03 & 56 \\
\hline Sand + Steel Chips $(5 \%)$ & Cube & 10.7 & 5.59 & 47.8 \\
\hline Sand + Steel Chips $(10 \%)$ & Cube & 9.5 & 4.85 & 49 \\
\hline Sand + Steel Chips $(15 \%)$ & Cube & 8.8 & 4.36 & 49.5 \\
\hline
\end{tabular}


Table 5. Grading parameters and dry compressive strength results.

\begin{tabular}{|c|c|c|c|c|c|c|c|c|c|}
\hline \multirow{2}{*}{$\begin{array}{l}\text { Aggregates } \\
\text { combinations }\end{array}$} & \multirow{2}{*}{$\begin{array}{c}\text { \% Passing sieve } \\
\text { No.25 }\end{array}$} & \multirow{2}{*}{$\begin{array}{c}\text { Grading } \\
\text { zone }\end{array}$} & \multirow{2}{*}{$\begin{array}{c}\text { Fineness } \\
\text { modulus (Fm) }\end{array}$} & \multirow{2}{*}{$\begin{array}{c}\text { Curvature } \\
\text { coefficient }\left(\mathbf{C}_{C}\right)\end{array}$} & \multirow{2}{*}{$\begin{array}{c}\text { Uniformity } \\
\text { coefficient }\left(\mathbf{C}_{U}\right)\end{array}$} & \multirow{2}{*}{$\begin{array}{l}\text { Sample type } \\
\text { (block/cube) }\end{array}$} & \multicolumn{3}{|c|}{$\begin{array}{c}\text { Compressive Strength } \\
\left(\mathrm{N} / \mathbf{m m}^{2}\right)\end{array}$} \\
\hline & & & & & & & 7-day & 14-day & 28-day \\
\hline Steel Chips & - & - & 6.57 & 0.92 & 2.3 & Chips & - & - & - \\
\hline Sand + Steel Chips $(0 \%)$ & 46 & 2 & 4.21 & 1.06 & 3.77 & Blocks & 1.69 & 2 & 2.8 \\
\hline Sand + Steel Chips $(1 \%)$ & 44.5 & 2 & - & - & - & Blocks & 1.71 & 2.22 & 2.88 \\
\hline Sand + Steel Chips $(2 \%)$ & 41 & 2 & - & - & - & Blocks & 1.76 & 2.51 & 2.96 \\
\hline Sand + Steel Chips (3\%) & 34.5 & 1 & - & - & - & Blocks & 2.85 & 3.36 & 5.34 \\
\hline Sand + Steel Chips $(4 \%)$ & 29 & 1 & - & - & - & Blocks & 3.35 & 3.66 & 5.62 \\
\hline Sand + Steel Chips $(5 \%)$ & 23.5 & 1 & 5.39 & 1.04 & 7.86 & Blocks & 3.19 & 3.64 & 5.44 \\
\hline Sand + Steel Chips $(10 \%)$ & 19.89 & 1 & 5.45 & 0.86 & 7.86 & Blocks & 2.3 & 3.5 & 4.14 \\
\hline Sand + Steel Chips $(15 \%)$ & 14.96 & 1 & 5.74 & 0.8 & 7 & Blocks & 1.8 & 2.34 & 3.3 \\
\hline Sand + Steel Chips $(0 \%)$ & 46 & 2 & 4.21 & 1.06 & 3.77 & Cubes & 6.7 & 7.5 & 10.83 \\
\hline Sand + Steel Chips $(1 \%)$ & 44.5 & 2 & - & - & - & Cubes & 7.3 & 8.3 & 11.24 \\
\hline Sand + Steel Chips $(2 \%)$ & 41 & 2 & - & - & - & Cubes & 8.4 & 9.8 & 11.25 \\
\hline Sand + Steel Chips $(3 \%)$ & 34.5 & 1 & - & - & - & Cubes & 9.1 & 10.88 & 11.7 \\
\hline Sand + Steel Chips $(4 \%)$ & 29 & 1 & - & - & - & Cubes & 9.25 & 11.35 & 12.8 \\
\hline Sand + Steel Chips $(5 \%)$ & 23.5 & 1 & 5.39 & 1.04 & 7.86 & Cubes & 8.4 & 10.7 & 11.5 \\
\hline Sand + Steel Chips $(10 \%)$ & 19.89 & 1 & 5.45 & 0.86 & 7.86 & Cubes & 8 & 9.5 & 11.3 \\
\hline Sand + Steel Chips $(15 \%)$ & 14.96 & 1 & 5.74 & 0.8 & 7 & Cubes & 7.5 & 8.8 & 11 \\
\hline
\end{tabular}




\section{Discussion}

From the compressive strength results tables and the plotted graphs for all the various sand and steel chip combination samples; the highest compressive strengths were recorded at the 28-day test (see Figures 6 and 7 below; Table 5 above).

Figure 6. Blocks Compressive Strength at $0,1 \%, 2 \%, 3 \%, 4 \%, 5 \%, 10 \%$ \& $15 \%$ Steel Chips.

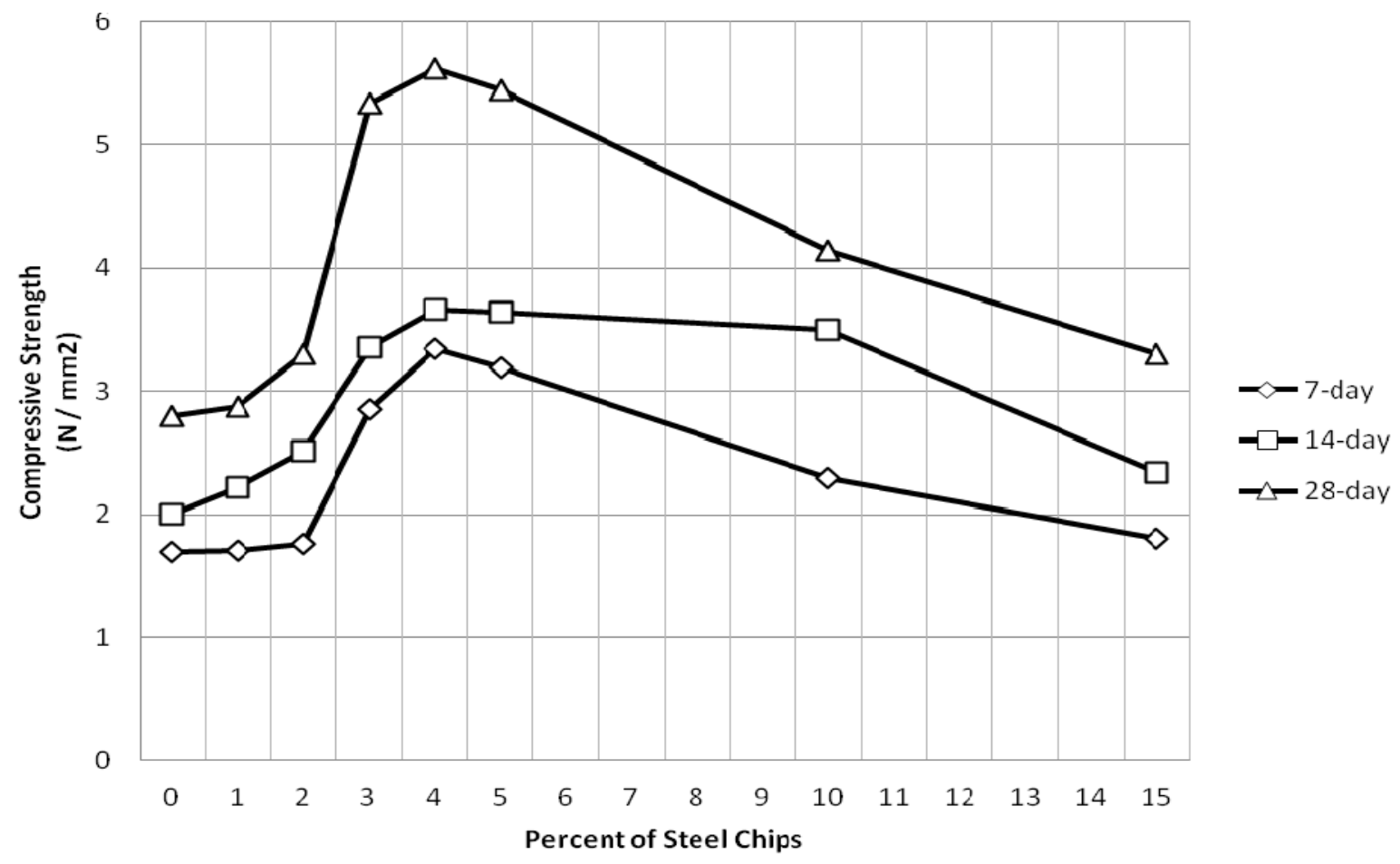

Figure 7. Cubes Compressive Strength at $0,1 \%, 2 \%, 3 \%, 4 \%, 5 \%, 10 \%$ \& $15 \%$ Steel Chips.

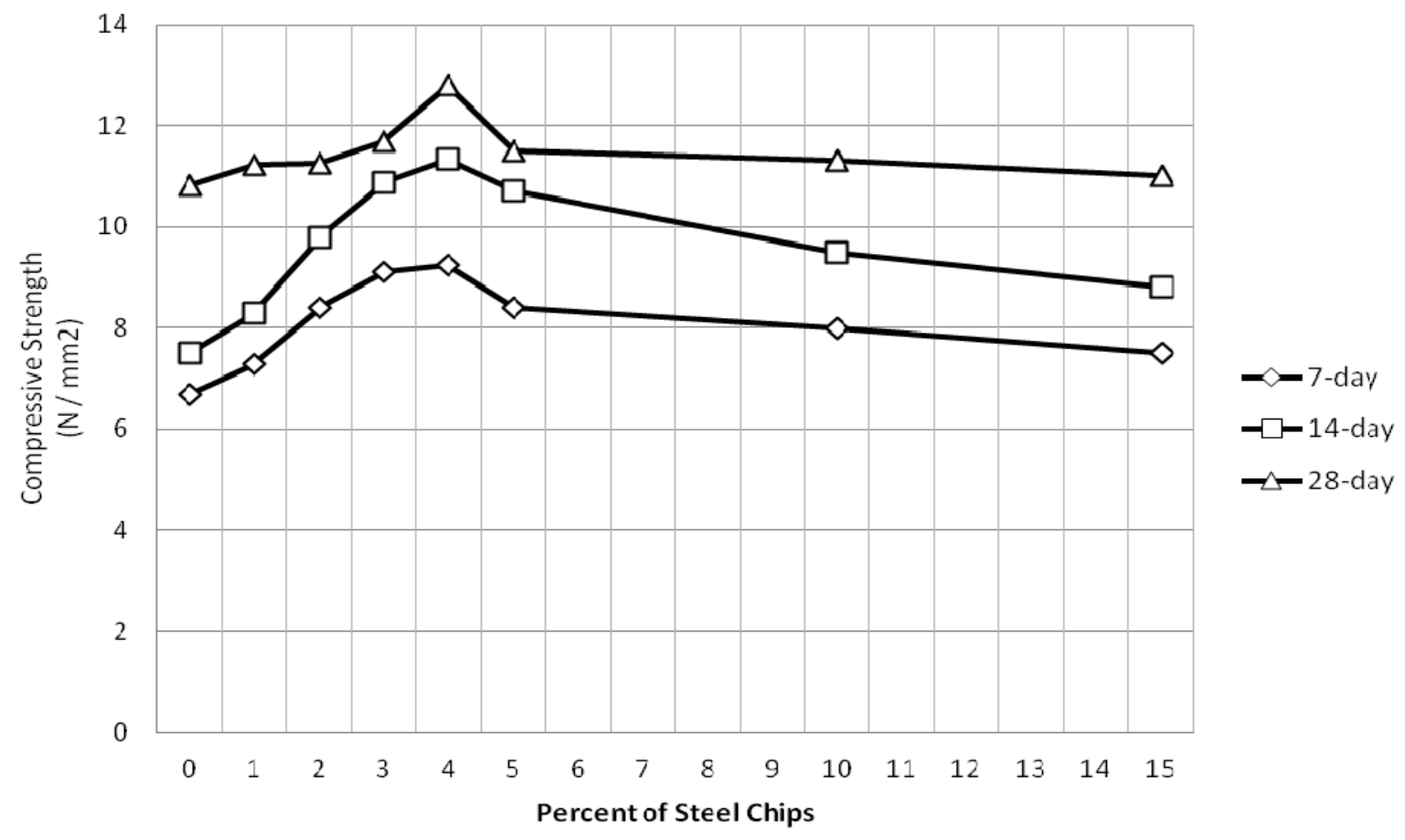


It was observed that the addition of steel chips led to an increase in compressive strength of the blocks and cube samples compared to non-inclusion of steel chips. However, it was interesting to discover in the first phase of this investigation that with an increasing percentage of steel chips, beyond the 5\% margin, there was a corresponding decrease in compressive strength values. In the first phase, the 5\% steel chip and sand combination gave the highest compressive strength at seven days, 14 days and 28 days respectively. The likely reasons for this finding include the aggregate grading or particle size distribution, rusting, stresses on the steel chips due to fabrication or machining, and possibly workmanship. The workmanship factor is the human factor (the possibility for experimental errors).

Waste steel chips, from the cutting and drilling of steel, are usually the product of fabrication by manually operated machining techniques in both developed and developing countries. In steel machining processes, cutting tools would normally travel along the surface of a workpiece and shear away part of the workpiece ahead of it. It is an energy intensive process and a sizeable portion of the energy expended is transformed into heat energy through mechanical-thermal interaction. This interaction excites the microscopic constituents of the interacting bodies. Most of this heat energy is stored or carried away by the chips, the waste product of the interaction of the cutting tool, and the workpiece, while the remaining smaller fraction of heat energy is shared between the tool and workpiece [17]. The resulting thermal equilibrium due to microscopic atomic interaction between the cutting tool, workpiece, and chips allow the various atoms to negotiate different energy levels from where they actually started (a spontaneous and irreversible process). In view of the fact that the bulk of the heat is carried by the steel chip a significant atomic displacement occurs within the material which leaves the steel chips severely stressed. Having been stressed by the processes of cutting and drilling during initial fabrication and working, in addition to the molding operations undertaken, the steel chips' ability to withstand further stress is greatly reduced. This could potentially lead to failure zones within the steel chips, even under low loads. Therefore, the higher the percentage of added steel chips, the higher the number of failure zones within the structural unit (sample). Equally pervasive, is the rate of corrosion in the steel chips, encouraged during the curing of the samples through the sprinkling/spraying of water.

In electrochemistry, corrosion is an electrochemical oxidation of metals in the presence of oxygen. The developmental process of iron oxide (rusting) is one of the well-known examples of electrochemical corrosion. In this process, water droplets in contact with the metal function as a voltaic cell with the potential to precipitate two simultaneous corrosive reactions. These reactions are oxidation and reduction reactions (commonly known as the redox reaction). It is important to mention here that it is practically impossible to have an oxidation reaction without a simultaneous reduction reaction. While oxidation is the loss of electrons, reduction refers to the gain of electrons. Thus, when a water droplet is in contact with a steel chip at the surface of the block or cubes, oxidation is induced automatically. This oxidation of metal (steel chip) takes place at the anode which is the corroded portion or pitting surface of the metal that releases iron (II) ions and negatively charged electrons $\left[\mathrm{Fe}(\right.$ solid $\left.)=\mathrm{Fe}_{2}^{+}(\mathrm{aq})+2 \mathrm{e}^{-}\right]$. These electrons flow within the metal to the outside or immediate edges of the water droplet (the cathode) to effect a corresponding reduction reaction. The reduction reaction occurs when released electrons from the anode are received at the cathode in the presence of oxygen and water to form hydroxide ions: $\left[\mathrm{O}_{2}\right.$ (gas) $+2 \mathrm{H}_{2} \mathrm{O}$ (liquid) $\left.+4 \mathrm{e}^{-}=4 \mathrm{OH}^{-}(\mathrm{aq})\right]$. The hydroxyl ions now move into the water droplets to react with the iron (II) ions from oxidation and which results in the 
precipitation of Iron (II) hydroxide. The Iron (II) hydroxide quickly oxidizes to form what is known as rust [18]. So rusting is the action of water on the steel in the presence of oxygen. It is an irreversible electrochemical process that reduces the strength properties of the steel with time. This accumulatively destructive phenomenon creates rust patches, which affect the binding matrix and the thorough adhesion of cement material. However, a far more likely reason for strength reduction as the steel chip percentage increases is the aggregate grading factor.

Ideally, the particle size distribution (variation in aggregate sizes) should be such that the finer particles fit into the spaces between the large particles leaving a minimum percentage of voids to be filled by the matrix in cementing the whole mass together. These voids - wherever they exist — are potential failure zones within the unit sample. The particle size distribution test (i.e., sieve analysis) carried out to ascertain the grading parameters of each of these aggregates showed that the combination of sand and 5\% steel chips was the best in comparison to the others during the first phase investigation (see Table 5 above, Figures 1 to 5). Generally, the grading performance (particle size distribution) of each of these combinations corresponded to their relative positions or performance during the compressive strength test. A sample of fine aggregate in grading zone one, implies sand with large particles, and the tendency for lower workability due to a slight reduction in the range of intermediate particles that could enhance bonding or dense packing. Arguably however, the larger the particle sizes the higher the specific surface area of these particles. This therefore means more particle contact area with the bonding or cementious material. Superficially, this appears to favor bonding. But there is a high tendency for the mix to become sticky and difficult to finish due to the reduction in intermediate particles [19]. A sticky mix is slightly difficult for placing and this impacts on its workability. This type of mix requires greater compaction to be effective. In view of the increase in numbers of voids within the mix matrix, if not addressed via the compaction process, these can significantly affect the compressive strength and finishing quality of the mix. On the other hand, finer sands lead to an increase in the water/cement ratio for a given workability, which in turn reduces the compressive strength. But the amount of water used in this investigation was fixed and a function of the difference between the optimum moisture content and the moisture content of the sand. So the likely variations of water/cement ratio due to the grading zone of the sand were not the subject of this investigation. However, the tendency for high compaction could have impacted on the compressive strength as all samples were subjected to a 20 -second vibration time. Thus, strength can be partly related to the grading of sands. It is partly related because several other factors outside constituent materials affect strength i.e., method of preparation, curing, and test conditions $[3,13,17,20]$. However, the coefficient of uniformity $\left(\mathrm{C}_{U}\right)$ grading parameter for $15 \%$ steel chip and sand combination is "7" (an indication of a greater range of particle size in sand). But the coefficient of curvature $\left(\mathrm{C}_{\mathrm{C}}\right)$ which defines the possibility of a dense packing was " 0.8 ". This value falls short of the range for well-graded soil $\left(1 \leq \mathrm{C}_{\mathrm{C}} \leq 3\right)$. Thus, the tendency for dense packing in the $15 \%$ steel chip and sand combination was lowest in this investigation (see Table 5).

It is also notable that the steel chip sandcrete hollow blocks achieved an average compressive strength of $5.44 \mathrm{~N} / \mathrm{mm}^{2}$ with a $5 \%$ steel chip and sand combination. These samples were also able to achieve $58.6 \%$ and $66.9 \%$ strength value at the 7 - and 14 -day crushing tests respectively.

Of particular interest was the wet compressive strength at the 14-day test. These results were within the range of $49 \%$ to $56 \%$, less than their dry compressive strength values (see Table 4). This 
comparison was necessary in view of the prevalent exposure conditions these blocks might be subjected to in the future, for example, if subjected to natural flooding. Information such as this would assist developers or builders in how to use these blocks in particular in the riverine areas and water-logged soils. It should also be noted that blocks used for external cladding and boundary walls, which are subject to driving rain or water-logged soil, are either partially of fully soaked with water. This could affect their compressive strength and this was why the wet compressive strength of the blocks after soaking in water for 14 days was determined [4].

Having seen and understood the compressive strength profiles for the sandcrete blocks and cubes samples with steel chips obtained during the first phase investigation, it became very important to ascertain the range or likely value of the steel chips for optimum compressive strengths for the blocks and cubes. This is to enhance the utility value of these products and in essence forms the crux of this investigation. As stated previously, lower proportions of added steel chips $(1 \%, 2 \%, 3 \%$ and $4 \%)$ to the sandcrete mix were investigated in this regard. Surprisingly, the results obtained revealed that the compressive strength produced at $4 \%$ added steel chips were slightly higher than that of 5\%, earlier verified in the first phase investigation (see Figures 6 and 7 above). However what was also significant was the fact that at 3\% added steel chips compressive strength was lower than that of $4 \%$ and $1 \%$ added steel chips produced compressive strength values lower than that of $3 \%$.

Therefore, the position of the optimum compressive strength values on the combined profile of both the first and second phase investigations (showing $0,1 \%, 2 \%, 3 \%, 4 \%, 5 \%, 10 \%$, and 15\%) for both sandcrete hollow blocks and cubes is actually positively skewed towards $4 \%$ level一or somewhere between $4 \%$ and $5 \%$ added steel chips to the sandcrete mix (see Figures 6 and 7 above).

\section{Recommendations}

- Steel chip sandcrete blocks are suitable for both internal load bearing and non-load bearing walls in areas where they are not subjected to moisture ingress. However, for external walls and in areas where they are liable to moisture attack (ingress) after laying, the surfaces should be well rendered. Below ground level, the surfaces should be coated with a waterproofing agent like bitumen.

- Waterproof Portland cement could also be used for the laying, manufacturing, and rendering of steel chip sandcrete blocks to prevent moisture ingress. This cement contains waterproofing agents and blocks made with it are less permeable to water. This allows the pores of the mortar to be filled or lined with a film of water repellent material.

- Owing to the high failure rate of sandcrete blocks in sub-Saharan Africa, most especially countries like Nigeria, a body should be set up to monitor and enforce the quality control process of sandcrete block making in that country. Subsidies for training at technical and further education colleges should be provided to counter the shortfall in technical skills and quality control in the manufacturing process.

\section{Conclusions}

This investigation has revealed that steel chips can be recycled if used as prescribed in this paper. The investigation also demonstrates that the addition of steel chips, in appropriate proportions, could considerably influence the compressive strength of sandcrete blocks and cubes. While the grading 
parameters of sand and steel chip combinations for the production of steel chip sandcrete blocks and cubes were improved, the margin of steel chips for optimum compressive strength was also ascertained. Thus the use of steel chip sandcrete blocks and cubes can enhance compressive strength and help the recycling of steel chips at a time when steel fabrication waste is of serious environmental concern globally.

\section{Acknowledgments}

Appreciation goes to Tim Parker (an associate from Leicester) and for his time and support in the proofreading of this paper.

\section{References}

1. Okpalla, D.; Ihaza, J. Quality of sandcrete blocks produced in Benin City. In Proceedings of the first Uniben Conference on Engineering and Technological Development, Benin City, Nigeria, 1987.

2. Omoregie, A.; Alutu, O. The influence of fine aggregate combinations on particle size distribution, grading parameters and compressive strength of sandcrete blocks. Can. J. Civil Eng. 2006, 33, 1271-1278.

3. Omoregie, A. Impact of vibration time on compressive strength of hardened sandcrete building blocks. Buildings 2012, 2, 153-172.

4. NIS (The Nigerian Industrial Standards). Draft Code of Practice for Sandcrete Blocks; NIS: Lagos, Nigeria, 1975.

5. Olusola, B.; Akintayo, O. An assessment of failure of building component in Nigeria. J. Build. Apprais. 2009, 4, 279-286.

6. Okolie, K.; Akagu, C. Quality Control in Building Delivery Process; Nigerian Institute of Architect: Abuja, Nigeria, 1994.

7. Alutu, O.E. Wind induced failure of pavilion roof in Ekpoma, implication for structural design and construction. Tech. Trans. 2000, 5, 15-20.

8. Nwokoye, D. The Philosophical Bases in Education and Practice of Structural Engineering; Ambik Press: Benin City, Nigeria, 1999.

9. Neville, A. Properties of Concrete; Longman: Essex, UK, 1996.

10. BSI (British Standards Institution). Test for General Properties of Aggregates. Part 1: Methods of Sampling; BSI: London, UK, 1997.

11. BSI. Methods of Test for Soils for Civil Engineering Purposes; BSI: London, UK, 1990.

12. BSI. Testing Aggregates. Method for Determination of Particle Size Distribution. Sieve Tests; BSI: London, UK, 1985.

13. Jackson, N.; Dhir, R. Civil Engineering Materials; Macmillian Press: London, UK, 1996.

14. Tezaghi, K.; Peck, R.; Mesri, G. Soil Mechanic in Engineering Practice, 3rd ed.; John Wiley and Sons: New York, NY, USA, 1996.

15. Illston, J.; Domone, P. Construction Materials: Their Nature and Behavior; Spon Press: New York, NY, USA, 2001. 
16. BSI. Methods for Test of Masonry Units: Determination of Compressive strength; BSI: London, UK, 2011.

17. Baumeister, T. Standard Handbook for Mechanical Engineers; McGraw-Hill: New York, NY, USA, 1967.

18. Charng, T.; Larsing, F. Review of Corossion Causes and Corossion Control in a Technical Facility; TDA Progress Report 42-69; NASA (National Aeronautics and Space Administration): Washington, DC, USA, 1982. Available online: http://ipnpr.jpl.nasa.gov/progress_report/4269/69O.PDF (accessed on 15 February 2013).

19. Lamond, J.E.; Pielert, J.H. Significance of Test and Properties of Concrete and Concrete Making Materials; ASTM International: West Conshohocken, PA, USA, 2006.

20. Neville, A.; Brooks, J. Concrete Technology; Scientific and Technical: London, UK, 1994.

(C) 2013 by the authors; licensee MDPI, Basel, Switzerland. This article is an open access article distributed under the terms and conditions of the Creative Commons Attribution license (http://creativecommons.org/licenses/by/3.0/). 